\title{
Insulin-like growth factor-I in Helicobacter pylori gastritis and response to eradication using bismuth based triple therapy
}

\begin{abstract}
Aims-To measure insulin-like growth factor-I (IGF-I) concentrations in the presence and absence of Helicobacter pylori infection and in response to eradication of the organism.

Methods-An enzyme linked immunosorbent assay was used to measure gastric and fasting serum concentrations of IGF-I in 17 patients with and 11 without $H$ pylori infection. Repeat assessments were performed in the infected patients six weeks after they received a two week course of bismuth chelate, metronidazole, and amoxycillin.

Results-IGF-I was detected at very low concentrations in gastric juice and in mucosal incubates. The median serum IGF-I concentration was $88 \mu \mathrm{g} / 1$ in the patients infected with $H$ pylori compared with $90 \mu \mathrm{g} / \mathrm{l}$ in the non-infected controls; IGF-I concentrations dropped to $77 \mu \mathrm{g} / 1$ following eradication therapy $(p=0.014)$. Conclusion-The similarity in baseline IGF-I concentrations in the presence and absence of $H$ pylori suggests that their subsequent drop after treatment is more likely to be due to the treatment.

(F Clin Pathol 1996;49:676-678)
\end{abstract}

Keywords: bismuth chelate, Helicobacter pylori, insulinlike growth factor-I.

Gastrointestinal

Centre, Southern

General Hospital,

Glasgow

A S Taha

R H R Park

A D Beattie

Department of Pathology

R Morton

Institute of

Pathological

Biochemistry,

University of Glasgow,

Glasgow

G Beastall

Correspondence to:

Dr A S Taha, Department of

Gastroenterology,

Eastbourne General

Eastbourne General

Eastbourne BN21 2UD.

Accepted for publication 7 May 1996
The biochemical basis of the increased gastric mucosal cell proliferation observed in Helicobacter pylori gastritis ${ }^{1}$ remains poorly understood. The action of $H$ pylori on the expression of insulin-like growth factor-I (IGF-I), an anabolic and mitogenic protein which has a key role in growth and development, is a possible cause of this increase in proliferation. ${ }^{2}$ The purpose of the present study, therefore, was to measure gastric and serum concentrations of IGF-I in patients with and without $H$ pylori infection, and following eradication therapy.

\section{Methods}

Adult patients were included if they were scheduled for upper gastrointestinal endoscopy, and excluded if they had any systemic illness, malignancy, gastric surgery, or if they had taken anti-ulcer drugs or antibiotics within one week of endoscopy. Ten microlitres of fasting $\overrightarrow{0}$ venous blood was taken and the serum was immediately separated and stored frozen at $-70^{\circ} \mathrm{C}$ pending analysis. Endoscopy was performed using 5-10 mg midazolam for sedation. Gastric antral and body biopsy specimens were taken to test for $H$ pylori infection by histology (two specimens), culture (one specimen) and urease activity (CLO-test; one specimen). Patients with $H$ pylori in any or all of these specimens were regarded as positive, and those lacking $H$ pylor $i$ in all specimens were considered negative. Specimens of fasting gastric juice were taken and frozen, and gastric antral biopsy specimens incubated overnight in RPMI 1640 prior to IGF-I measurements.

Gastritis was classified according to the Sydney system and its activity graded on a scale from 0 to 3 as follows: $0=$ normal; $1=$ mild; 2 $=$ moderate; and 3 = severe, depending on the intensity of neutrophilic infiltration.

In patients infected with $H$ pylori all assessments were repeated six weeks after completion of a two week eradication regimen, comprising metronidazole ( $400 \mathrm{mg}$ three times daily), amoxycillin (500 mg three times daily) and bismuth chelate (De-Nol; $120 \mathrm{mg}$ four times daily). IGF-I concentrations were measured using an enzyme linked immunosorbent assay, with a sensitivity of $10 \mu \mathrm{g} / 1$, and using an antibody that does not cross-react with insulin pro-insulin, or IGF-II.

Statistical analyses included the MannWhitney U test and the Wilcoxon's test for unpaired and paired data, respectively. Informed consent was obtained from all patients and all specimens were coded prior to analysis. The study was approved by the local Ethics Committee.

\section{Results}

Twenty nine patients were studied, 18 of whom were positive and 11 negative for $H$ pylori infection. In the infected group the triple therapy regimen failed to eradicate $H$ pylor $i$ in five patients. The baseline serum sample of one $H$ pylori positive patient was lost during processing, and another patient refused triple therapy altogether. This left 28 patients (17 positive and 11 negative for $H$ pylori) with baseline specimens and 11 patients with specimens taken both before and after eradication therapy. 
Table 1 Patient characteristics

\begin{tabular}{lcc}
\hline & \multicolumn{2}{l}{ Patients } \\
\cline { 2 - 3 } & H pylori positive & H pylori negative \\
\hline Number & 17 & 11 \\
Male:female ratio & $9: 8$ & $5: 6$ \\
Age (years) & $48(43-57)$ & $54(40-63)$ \\
Smokers & 10 & 7 \\
Alcohol drinkers & 10 & 8 \\
Duodenal ulcer & 2 & 0 \\
Gastric ulcer & 1 & 1 \\
Grade of gastritis activity & & \\
0 (normal) & 1 & 8 \\
1 (mild) & 7 & 3 \\
2 (moderate) & 6 & 0 \\
3 (severe) & 3 & 0 \\
\hline
\end{tabular}

^Median (interquartile range).

The characteristics of patients are shown in table 1. Patients were comparable with respect to their sex, age, smoking and drinking habits, and endoscopic findings. All but one of the $H$ pylori positive patients had varying degrees of active gastritis, while eight $(73 \%)$ of $11 \mathrm{H}$ pylori negative subjects had normal gastric histology. IGF-I was detectable only at a very low concentrations in gastric juice and tissue incubates and, therefore, statistical comparison was not possible in these specimens.

Serum IGF-I concentrations in the presence or absence of $H$ pylori are shown in fig $1 \mathrm{~A}$, and were similar in both groups. The effect of successful $H$ pylori eradication on serum IGF-I concentrations is shown in fig $1 \mathrm{~B}$. Post-triple therapy values are significantly lower than those at baseline. No significant change in IGF-I concentrations was noted in patients with persistent $H$ pylor $i$ infection, probably due to poor compliance with therapy, and these were excluded from statistical analysis. It is also worth noting that the successfully treated group $(n=11)$ included four patients with grade 1 , five with grade 2 , and two with grade 3 gastritis at baseline, compared with 10 patients with normal gastric histology (grade 0 ) and one patient with mild gastritis (grade 1) after successful eradication of the infection.
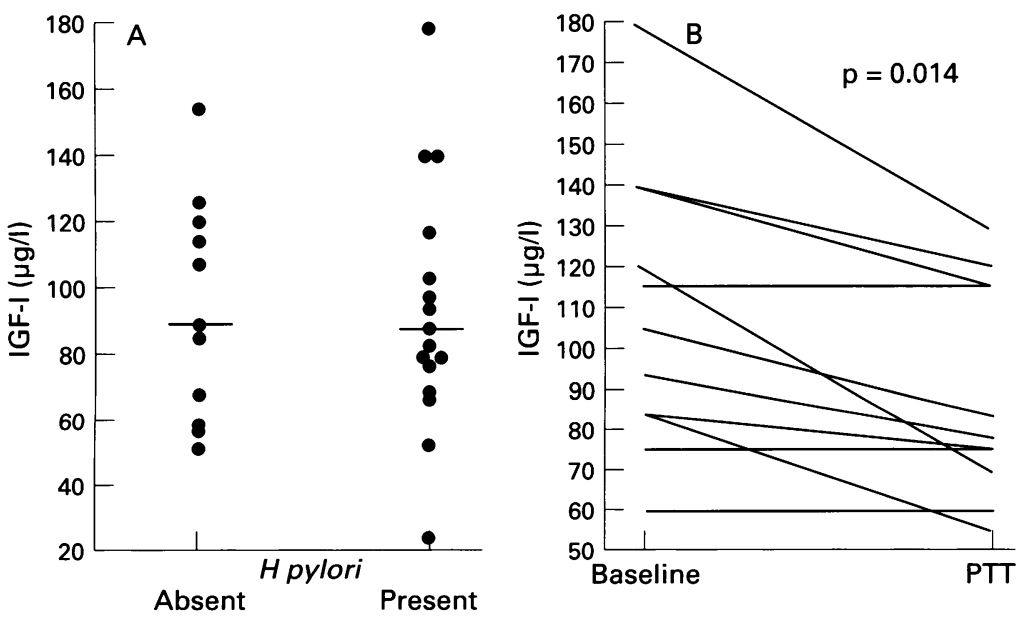

Figure 1 (A) IGF-I fasting serum concentrations in $\mathrm{H}$ pylori positive patients and their negative counterparts. (B) A significant drop in IGF-I concentrations was observed six weeks post triple therapy (PTT) following successful eradication.

\section{Discussion}

This study shows that fasting serum IGF-I concentrations are not influenced by the presence of $H$ pylori gastritis, although they did fall significantly in response to a two week course of bismuth based triple therapy.

With the increasing evidence linking $H$ pylor with gastric mucosal cell proliferation, ${ }^{1}$ one could not exclude the possibility that IGF-I concentrations might be influenced by the presence of this organism. This was not confirmed by our study and suggests the involvement of other factors in $H$ pylori related mucosal cell proliferation. ${ }^{1}$

The similarity in IGF-I concentrations in patients with and without $H$ pylori infection, with different grades of gastritis, suggests that it is unlikely that IGF-I is expressed in measurable amounts by the neutrophils in vivo, given the role of the neutrophils as an index of the activity of gastritis. This also explains the absence of high concentrations of IGF-I in gastric juice or tissue, as assessed in the present study.

There are two possible explanations for the drop in serum IGF-I concentrations following eradication of $H$ pylori. The first relates to the normalisation of gastric histology. This, however, does not reconcile the differences in the activity of gastritis in patients with and without $H$ pylori infection given the similarity in baseline IGF-I concentrations in these patients. The second, and probably the more likely explanation, is a direct inhibitory effect of bismuth based triple therapy on IGF-I production. This might explain another effect of triple therapy, thought to be independent of $H$ pylori: it has been found that gastric mucosal cell proliferation decreased-that is, returned to normal four weeks after the intake of triple therapy, irrespective of the patient's $H$ pylor status. ${ }^{1}$ It will therefore be interesting, should ethical approval be forthcoming, to investigate the effect of triple therapy on $H$ pylori negative subjects when the consequences of eradication are studied.

The pathophysiological properties of IGF-I and the ability to produce it by recombinant DNA techniques have led to extensive testing of its "endocrine" activities. IGF-I stimulates glucose disposal in a manner similar to insulin and can increase insulin sensitivity, ${ }^{3}$ raising the possibility of an application in insulin resistant syndromes. ${ }^{4}$ In catabolic subjects, intravenous IGF-I reverses nitrogen loss, ${ }^{5}$ whereas recovery from both ischaemic renal necrosis ${ }^{6}$ and dermal wounding ${ }^{7}$ can be accelerated by subcutaneous or local administration. However, IGF-I has also been linked to the development of a variety of neoplastic diseases including those of the breast, stomach, liver, and colon. ${ }^{8} 9$ To date, no agent has been shown to suppress IGF-I production, and this highlights the therapeutic potential of our findings.

In conclusion, $H$ pylori infection does not seem to alter IGF-I concentrations despite the differences in the activity of gastritis in patients with and without $H$ pylori infection. Fasting serum IGF-I concentrations are, however, sup- 
pressed by bismuth based triple therapy and this might have therapeutic implications.

The authors thank Dr Wilson Angerson for his help with the statistical analysis and Mrs Jane Dickson for secretarial assistance.

1 Lynch DAF, Mapstone NP, Clarke AMT, Sobala GM, Jackson $\mathrm{P}$, Morrison L, et al. Cell proliferation in Helicobacte pylori associated gastritis and the effect of eradication therapy. Gut 1995;36:346-50.

2 Le Roith D, Clemmons D, Nissley P, Rechler MM. Insulinlike growth factors in health and disease. Ann Intern Med 1992;116:854-62.

3 Zenobi PD, Graf S, Ursprung H, Froesch ER. Effects of insulin-like growth factor-I on glucose tolerance, insulin levels and insulin secretion. F Clin Invest 1992;89:190813 .

4 Usala Al, Madigan T, Burguera B, Sinha MK, Caro JF, Cunningham $\mathrm{P}$, et al. Treatment of insulin-resistant diabetic ketoacidosis with insulin-like growth factor-I in an adolescent with insulin-dependent diabetes. $N$ Engl $\mathcal{F}$ Med 1992;327:853-7.

5 Clemmons DR, Smith-Banks A, Underwood LE. Reversal of diet-induced catabolism by infusion of recombinant insulin-like growth factor-I in humans. $\mathcal{f}$ Clin Endocrinol Metab 1992;75:234-8.

6 Miller SB, Martin DR, Kissane J, Hammerman MR. Insulin-like growth factor-I accelerates recovery from ischaemic acute tubular necrosis in the rat. Proc Natl Acad Sci USA 1992;89:11876-80.

7 Suh DY, Hunt TK, Spencer EM. Insulin-like growth factor-1 reverses the impairment of wound healing induced by corticosteroids in rats. Endocrinology 1992; 131:2399-403.

8 Guo YS, Beauchamp Rd, Jin GF, Townsend CM, Thompson JC. Insulin-like growth factor-binding protein modulates the growth response to insulin-like growth factor 1 by human gastric cancer cells. Gastroenterology 1993; 104: 1595-604

9 Singh P, Rubin N. Insulin-like growth factors and binding proteins in colon cancer. Gastroenterology 1993;105:1218-37. 